\title{
Afetos analógicos nos filmes Elena, de Petra Costa e Adieu Monde, de Sandra Kogut
}

\author{
Bárbara Bergamaschi Novaes*
}

Elena (Brasil, 2012, $82 \mathrm{~min}$.)

Direção: Petra Costa

Roteiro: Petra Costa, Carolina Ziskind

Produção executiva: Julia Bock, Daniela Santos

Montagem: Marilia Moraes, Tina Baz

Som direto: Edson Secco

Adieu Monde (ou L'Histoire de Pierre et Claire) (França, 1997, 27 min.)

Direção: Sandra Kogut

Roteiro: Sandra Kogut

Produção Executiva: Catherine Derosier

Montagem: Sandra Kogut

Som Direto: Pierre-Emannuel Poizat

No documentário elegíaco Elena (2012), a diretora Petra Costa investiga seu passado familiar através do resgate da história de sua irmã mais velha que dá nome ao filme, Elena. Petra constrói sua narrativa em uma aproximação dupla do outro e de si mesma, auto-(e)-biográfica. As imagens do filme entrecruzam tempos e no seu trajeto traçam um caminho que alterna entre os movimentos do histórico e do testemunho, no limiar entre a zona afetiva da memória, o universo onírico e o documental.

A montagem do filme Elena entrecruza "correntes"do tempo, utilizandose de uma gama eclética de texturas de imagens de arquivos familiares, vindas de suportes analógicos tais como: Super-8 e o VHS, Petra resgata mais de 50 horas de vídeos caseiros acumulados desde os anos de 1980. Estas imagens do passado se misturam com imagens atuais da diretora andando pela cidade de Nova York, filmadas com uma câmera Super 8, uma digital DSLR profissional e do celular iPhone. As imagens analógicas de VHS e Super 8, atuais e do passado se misturam na diegése criando uma nova temporalidade onde as irmãs podem finalmente se reencontrar.

* Doutoranda no programa de Pós-Graduação em Comunicação e Cultura (PPGCOM) pela ECO-UFRJ e no Programa de PPGLCC da PUC-Rio.

E-mail: barbarabergg@gmail.com 
Em Adieu Monde (1997), de Sandra Kogut, também observamos a mistura de tempos pautada pela mudança do suporte fílmico através da textura e materialidade do Super 8 e do VHS. No média-metragem feito para a televisão francesa, a cineasta Sandra Kogut vai à região dos Pirineus e entrevista moradores dos pequenos vilarejos D'Aspe e D'Ossav. A região atrai turistas do mundo todo interessados na "autêntica" experiência da campagne francesa, onde supostamente a cultura francesa tradicional se manteve intacta dos ritmos frenéticos da globalização. Sandra Kogut, de forma distinta de Petra Costa, não mescla o real e o virtual através do recurso de imagens Super 8 e vHS; ela cria dois universos: o documental e o onírico e demonstra como um vai contaminando e alterando o outro a medida que se constituem.

Os aspectos plásticos da linguagem do filme Super 8 são muito característicos. Nesse tipo de imagem torna-se perceptível a passagem do tempo, pois as imagens carregam em si as marcas físicas impregnadas na película, como uma patina do tempo. Além disso, é possível perceber uma precariedade nas imagens, pois são resultados de uma prática amadora de registro do vídeo em que se filma com a câmera na mão, o que faz com que a imagem fique tremida ou borrada, o som muitas vezes é dessincronizado, não há a presença de uma a montagem articulada a priori, apenas fragmentos rápidos, entre outras características formais. Nesses dois filmes o Super 8 e o VHS são utilizados tanto como uma prática da reminiscência e rememoração, quanto como produtor de passados fabricados que nunca ocorreram como tal no "real". A imagem analógica nos filmes atua tanto como máscara mortuária, fazendo seu papel ontológico de documento, operando como arquivo, prova irrefutável de um acontecimento, invocando uma nostalgia do passado; mas também trabalha a serviço do sonho, da criação, da ficcionalização do real, dos desejos e devaneios de seus autores.

\section{A imagem imortal}

Narrado em primeira pessoa, o longa-metragem Elena é estruturado em dois blocos. Na primeira, em um crescendo, como no gênero cinematográfico thriller, o filme vai lentamente envolvendo o espectador no seu mistério. Logo no início intui-se que algo perverso ou cruel ocorreu com Elena, pois a protagonista não está em parte alguma. Elena é, desde o princípio, apresentada como enigma, já transfigurada em sombra do passado, é uma presença ausente, espécie de entidade mnemônica que paira sob as imagens. Como em um filme de trama policial, o enredo vai amarrando o espectador diante da expectativa de saber a resolução: afinal o que aconteceu com Elena? Após a revelação do seu suícidio, o filme então se encaminha para seu segundo "bloco" agora vol- 
tado para a diretora e sua mãe. Vemos, nesta segunda metade do filme, como a ausência e o vazio deixados pela morte impactaram os que ficaram. O filme explora a dor e a culpa privilegiando o ponto de vista feminino pois, curiosamente, o pai de Elena não é retratado, a não ser rapidamente em imagens de arquivo.

A relação do cinema e da fotografia com a morte é um tema recorrente em debates teóricos e filosóficos acerca da essência ontológica das imagens. Bazin (1983: 121) em seu famoso texto Ontologia da Imagem Fotográfica relaciona o cinema à morte e à relíquia ao compará-lo às múmias do antigo Egito. Para Bazin, uma das necessidades fundamentais da psicologia humana é a defesa contra o tempo e a morte. Assim, na religião egípcia, com suas práticas de preservação do corpo, o homem pôde triunfar sobre a morte através da conservação da aparência. No cinema, igualmente temos a preservação e congelamento do tempo através da representação da imagem. Barthes (1984: 124) também faz a mesma alusão em seus textos na Câmara Clara, mas comparando a fotografia ao Santo Sudário de Turim, considerando que são duas imagens produzidas por contato direto físico com o referente, sem interferência da mão humana. Este desejo humano de eternidade e de luta contra o esquecimento seria o princípio fundador de todas as artes da representação.

A teoria de Barthes (1984) em A Câmara Clara institui o conceito de çaéte - traduzido: isto foi - centrado na questão do tempo passado. A fotografia é tratada como um vestígio que só é capaz de apontar para uma existência do passado. O noema constitutivo da fotografia, expresso pela ideia do "ça-été". Esta noção reiterava o conceito em torno da natureza documental da fotografia. Factível, irrefutável e atrelada ao real ("é isso!"), para Barthes a fotografia se tratava de representação necessariamente dependente de um objeto real préexistente, uma marca aparente do referente sem mediação. A Fotografia para Barthes é, portanto, fundamentalmente calcada em um tempo passado. Ela se configura como um atestado de que aquilo existiu e se foi, de uma eterna morte, de um tempo que não voltará mais.

Assim, esses autores reclamam um status fundador para a imagem fotográfica e cinematográfica, aproximando sua origem do teológico, do sagrado, da magia e da relíquia. A fotografia, portanto, pode ser vista não apenas como uma representação, mas como um objeto dotado de valor simbólico, emocional e econômico. Além disso, a Fotografia seria capaz de, nas palavras de Barthes (1984: 132) , "emanar' um real. A fotografia não seria uma representação, mas sim uma "presença" do passado que impregnou o papel fotográfico. Esta verificação do passado e do futuro no presente é o que punge o espectador, que se sente olhado, "apunhalado"pela imagem. 
Em uma primeira instância, as imagens de Petra Costa evocam estes pontos ontológicos do meio cinematográfico: a relação com a morte. Vemos a todo instante a imagem de Elena em VHS e Super 8 e sabemos que em breve, diegeticamente, Elena não estará mais entre nós. Mas também temos a consciência, extra-diegeticamente, que Elena já morreu, não há nada que possa ser feito. Há uma constante atualização e virtualização do passado no decorrer do filme. As imagens analógicas do filme nos lembram a todo o momento a iminência da morte que paira sob todos nós. Em uma percepção mais imediata, o filme nos joga nesta relação nostálgica com o passado, um sentimento melancólico de desejo de volta para tempos outros. Entretanto, apesar de elegíaco, ou seja, tendo seu fio narrativo todo sustentado em cima de uma morte, o documentário de Petra Costa não se limita a uma relação memorialista nostálgica voltado unicamente para o tempo decorrido. Esta seria apenas uma primeira camada do filme.

Na primeira metade de Elena, o filme dança com a morte e se aproxima do abismo correndo risco de cair em uma repetição da morte ad infinitum como muitos filmes documentários clássicos o fazem: exumam um cadáver, trazemno de volta à vida apenas para matá-lo novamente. A autora Susan Sontag (1981) já alertava para o poder do fotógrafo de "matar" mesmo que metaforicamente os seus retratados:

Fotografar é apropriar-se da coisa fotografada. É envolver-se numa certa relação com o mundo que se assemelha com o conhecimento - e, por conseguinte com o poder. (...) fotografar pessoas é violá-las e vê-las como jamais podem ver-se a si próprias, conhecê-las como nunca poderão conhecer-se; é transformá-las em objetos de cuja posse nos asseguramos simbolicamente. A máquina fotográfica não domina, embora o faça crer, penetre, invada, distorça, explore e usando a metáfora em sua força máxima, assassine (...). (Sontag, 1981: 14).

Como, então, evitar uma espetacularização da morte em filmes que tratam de temas tão delicados quanto o suicídio? Uma das possíveis respostas estaria na ficção. É no "falso documentário" e nas "potências do falso" em que se opera a clássica cura catártica aristotélica na diretora. A utilização de imagens com referentes semióticos do passado como artifício, vem para problematizar o gênero documental, bem com a indicialidade, a ontologia e os discursos "tradicionais" da veracidade das imagens fotográficas.

\section{A Imagem Imemorial}

Petra declarou em entrevista o seguinte sobre o processo de criação do filme Elena: 
"Foi uma mistura de prazer e dor. (...) Ao longo do filme ela foi virando um ser humano, de carne e osso, com diversas características. O processo era como se eu constantemente estivesse ganhando uma irmã para em seguida perdê-la de novo, já que percebia que ela não estava mais presente. Ao mesmo tempo, a dor foi muito grande porque tinha muito mais consciência para entender o que realmente aconteceu e o quão trágico foi. " 1 .

Segundo Jeanne Marie Gagnebin (2006: 99), é próprio da experiência traumática uma impossibilidade do esquecimento e uma insistência na repetição. Assim, seu primeiro esforço consiste em tentar dizer o indizível, numa tentativa de elaboração simbólica do trauma que permite continuar a viver e, simultaneamente, numa atitude de testemunha de algo que não pode nem deve ser apagado da memória e da consciência da humanidade.

Petra tinha apenas sete anos quando Elena, sua irmã, morreu. A mãe de Petra revela, na segunda parte do filme, que ela quando criança desenvolveu estranhas compulsões: não querer se olhar no espelho por medo de morrer. Percebemos no desenrolar da narrativa que todo o argumento do filme está fundamentado na relação especular dessas três mulheres: Petra, Elena e sua Mãe. A mãe almejava ser atriz e abriu mão do sonho para constituir família, casar, etc. O filme demonstra como um desejo é transferido inconscientemente através das gerações. Elena tentou dar continuidade ao desejo da mãe e falhou, Petra, que também se torna atriz, dançarina, artista, enfim assume a responsabilidade, mesmo que de forma inconsciente, na tentativa de dar um desfecho e cicatrizar a ferida familiar. O filme já denota esta chave especular no seu começo quando Petra relata um sonho em que ela se confunde com Elena e morre em seu lugar: "me vejo tanto em suas palavras que começo a me perder em você".

Não são poucos os autores que procuram traçar um paralelo entre o cinema e o funcionamento da mente humana. Baudry (1970) afirma: "a tela nos remete ao espelho de nossa infância, no qual vimos um corpo (o nosso) se refletir e nos reconhecemos nos traços de Outro". A tela remete a uma espécie de imagem especular do eu espectatorial, sem ser, propriamente falando, um espelho refletor. (Aumont, 2003: 107-108). Já Arlindo Machado (2011) sugere que Freud utiliza o aparato fotográfico como figura de linguagem para explicar o inconsciente. Para o autor, não é apenas uma coincidência o fato de as instituições do cinema e da psicanálise terem nascido praticamente ao mesmo tempo. "Um como o outro buscam realizar essa fusão impossível da ciência com o irracional: são máquinas e métodos positivistas a serviço do delírio do espírito."

1. Entrevista exclusiva - Petra Costa fala sobre o documentário Elena Por AdoroCinema 09/05/2013 às 08:01 disponível em www.adorocinema.com/noticias/filmes/noticia-102960/ 
O filme Elena é estruturado no imbricamento de três distintas camadas ou fluxos de tempo que se entrecruzam de forma intermitente na montagem. O primeiro é o do tempo cartesiano, linear, cronológico, factual, objetivo, histórico e jornalístico. É como o filme começa: Petra conta na primeira pessoa em off a história do encontro de seus pais, passando pela luta na guerrilha e posterior exílio durante a ditadura militar, nascimento de Elena, sua infância, até chegar ao clímax na cidade de Nova York. A segunda camada é a do tempo subjetivo, é o tempo da memória, dos afetos, dos sonhos e devaneios da diretora, que são narrados em voz off. Este segundo fluxo é inclusive representado pela imagem literal de um Rio. Petra cria uma mise-en-scene em que várias mulheres são filmadas boiando sendo levadas pela correnteza das águas, em uma clara referência à personagem feminina Ofélia ${ }^{2}$ da tragédia de Shakespeare Hamlet - imagem que remete também ao suicídio da escritora Viriginia Woolf. Finalmente, a terceira camada de tempo é a atual, o imediato, do agora, o tempo presente. São imagens de Petra e a mãe perambulando por Nova York. Como num filme policial, de detetive, elas seguem os rastros deixados por Elena. Orientando-se por anotações de arquivos, diários e registros sonoros deixados pela garota, as duas andam pela cidade visitando os lugares por onde a jovem esteve: a universidade, o apartamento onde morava, as ruas por onde passava, culminando no hospital onde morreu. ${ }^{3}$

Para o teórico Hugo Munsterberg (1983: 41), só o cinema é capaz de dar corpo à divisão interna da mente e só ele consegue representar a 'consciência das situações contrastantes, a este intercâmbio de experiências divergentes do espírito.' Ele assinala que a mente humana é partida, pode estar em vários lugares simultâneos em um mesmo estado mental. 'A memória se relaciona com o passado, a expectativa e a imaginação com o futuro' e mente humana não avançaria numa única direção, mas sim 'as múltiplas correntes paralelas e suas infinitas interligações constituem a verdadeira essência do entendimento. (...) Só o cinema faculta tal onipresença.' (1983: 43). E ainda Andre Bazin (1983: 159) afirma que a percepção humana é capaz de apreender vários instantes no espaço de um tempo durável, porém para nossa consciência nenhum desses instantes se repetem, podem apenas se assemelhar, mas nunca serão idênticos

2. Retratada com recorrência pelos pintores pré-rafaelitas, Ofélia encarna a figura da mulher que dominada pela suas paixões é levada à loucura e se afoga ao ser tragada pelas fortes correntezas do rio. Figura alegórica da donzela ingênua e apaixonada, Ofélia é também uma personagem misteriosa na obra de Shakespeare pois não se sabe se sua morte foi acidental ou suicídio consumado. Figura trágica pois é resultado de um jogo de forças políticas além do seu conhecimento (maquinações do destino), Ofélia é levada a acreditar que Hamlet não a amava mais, quando este estava apenas encenando uma falsa loucura para desvendar o mistério da morte de seu pai.

3. Este trecho do filme beira o sensacionalismo, em que as personagens insinuam discursos de denuncia de erro e negligência médica há uma perigosa aproximação da espetacularização da morte de Elena. 
aos outros. Assim, é somente no cinema onde podemos ver e rever os instantes do tempo passado, 'como se este fosse uma réplica objetiva da memória'. O cineasta Luis Buñuel (1983: 336) afirma que o cinema "é o melhor instrumento para exprimir o mundo dos sonhos, do instinto."

Como na memória, a montagem do filme de Petra Costa trabalha usando os tempos-cruzados, não cronológicos. O uso da estética do Super 8 e do VHS do filme Elena, misturados a imagens atuais e do passado, feitas com esses mesmos aparelhos, produz uma confusão temporal no espectador, que se pergunta se está vendo imagens do tempo atual ou se imagens de arquivo do tempo em que Elena estava viva. Também o desenho de som de Elena e das narrações em voz off acentuam esta temporalidade-outra inaugurada pelo meio fílmico. Petra imprime também na banda sonora sua própria voz em off, com suas impressões, memórias e sentimentos a respeito da irmã, muitas vezes acrescentando trechos novos aos diários, completando as falas da irmã. As vozes das duas irmãs, como em um balé, vão se misturando, jogando uma com a outra. Pela semelhança do timbre, da cadência e do sotaque entre as duas, já não sabemos mais qual irmã que fala. Através da mistura das materialidades fílmicas, a diretora é capaz de reproduzir e organizar o tecido de sua memória, representando a constelação de elementos que compõem a realidade do mundo que a impregna. O filme Elena dá corpo às múltiplas correntes e infinitas interligações que a atravessam, representando o "continuum sensível" da mente humana.

Os temas da memória e do tempo são caros ao filósofo Walter Benjamin que irá, em diversas obras, dissertar sobre a ideia do tempo entrecruzado e da rememoração. Segundo Lissovsky (2005), em Benjamin uma das características mais importantes da memória seria o fato de ela não ser unidirecional. A memória não seria um movimento que surge no presente e se volta para o passado (como nos sugere a idéia de rememoração), mas sim bidirecional, onde o passado visa, na mesma medida em que é visado, o futuro. O agora de Benjamin é o lugar e a ocasião em que passado e futuro visam um ao outro, onde eles se tocam. É neste reencontro de tempos em que os acontecimentos poeticamente transfigurados pela memória são apreendidos como imagem, no instante em que são "reconhecidos", isto é, no agora. As imagens da história que Benjamin nos oferece não podem ser acessadas de forma intencional, racional ou mecânica, mas sim como propõe Proust de forma involuntária, através de um choque no presente, onde ocorre o "desvelamento"dessa memória, no encontro dialético de tempos. Este seria o trabalho da reminiscência realizado por Proust em seu livro Em busca do Tempo Perdido, um trabalho não de reflexão, mas de presentificação. 
Benjamin também argumenta que na memória individual é possível vislumbrar traços das memórias coletivas - as memórias subjetivas teriam a capacidade de reconectar a experiência da sociedade com sua história, a confluência do passado e do presente, do íntimo e público criam-se imagens históricas. A memória abrigaria não somente o que passou mas sobretudo, como cada época sonhou seus futuros irrealizados (Lissovsky, 2005: 11) . O filme autobiográfico e familiar de Petra não é um caso isolado. Segundo Gagnebin (2006), narrativas e literatura de testemunho e relatos autobiográficos se tornaram um gênero tristemente recorrente do século XX. Depois de duas Guerras Mundiais e, sobretudo, depois da Shoah, a temática do trauma torna-se predominante na reflexão sobre a memória contemporânea. Os reflexos deste movimento também podem ser observados dentro do território dos estudos do cinema e da crítica cinematográfica. Filmes de amador, filmes de família, filmes autobiográficos se tornaram relevantes particularmente a partir dos anos 1980. O filme Elena pode ser colocado dentro dessa categoria de filmes, pois se localiza dentro deste fenômeno contemporâneo, onde memória individual e subjetiva pode servir a uma memória coletiva e social. Quantos artistas brasileiros não passaram pela mesma situação de desespero que Elena na era Collor?

Um outro ponto interessante que o filme de Petra Costa nos levanta é a distinção de dois conceitos de Benjamin: Erinnerung em oposição à Eingedenken, rememoração e reminiscências, respectivamente. O primeiro estaria associado às comemorações, às celebrações oficiais do estado, corresponderia ao papel tradicional do historiador que documenta e arquiva. Em contraposição, o segundo conceito diz respeito à reminiscência, operação realizada por Proust que consiste em trazer o passado para o agora, agindo sobre ele, visando transformar o presente. Gagnenbin (2006: 98) lembra que Nietzsche já descrevia essas transformações culturais dos usos e do valor da memória; denunciava, em particular, a acumulação obsessiva e a erudição vazia do historicismo cujo efeito maior não consistia numa conservação do passado, mas numa paralisia do presente. Há um esquecer natural, feliz, necessário à vida, dizia Nietzsche. Mas existem também outras formas de esquecimento, duvidosas: não saber, fazer de conta que não se sabe, denegar, recalcar. Tanto Nietzsche, quanto Benjamin já alertavam para os excessos de uma cultura memorialista que não se permite esquecer, tendência, que segundo alguns teóricos, está alcançando o seu ápice na contemporaneidade.

O filme de Petra, portanto, consegue não se limitar a uma rememoração infértil e melancólica, alertada por Nietzsche, e não se paralisa diante de um apego a um passado, mas busca superá-lo. Ao realizar o cruzamento de três camadas ou correntes de tempo Elena, experimentamos o procedimento dialé- 
tico de atualização do passado, onde passado e futuro se encontram no "agora" Benjaminiano. É na construção dessa nova temporalidade, a dos afetos, onde as duas irmãs podem se encontrar como adultas, conversam, se olham, se escutam, por fim podem habitar o mesmo "universo". Assim, Petra parece conseguir lidar com sua obsessão narcísica com a irmã: capturando o prófílmico transmutando-o em acontecimento poético, no espaço diegético - lá ela pode reencontrar a irmã perdida, desejada, sonhada e fetichizada, superando o trauma e seguindo adiante.

\section{O aceno da Aura e do Narrador}

Jeanne Marie Gagnebin (2006: 41) ressalta que toda literatura moderna e contemporânea estão calcadas no "fim das grandes narrativas". Esta perda já vinha sendo alertada por Benjamin em dois ensaios que tratam deste tema: "Experiência e pobreza"e "O narrador". Para o autor, a modernidade é marcada pelo empobrecimento da experiência. Gagnebin (2006: 110) observa que Benjamin viveu na Alemanha do Entre Guerras e ficou especialmente consternado com os soldados que voltavam do front: notou que voltavam todos mudos, sem capacidade de falar dos horrores que haviam presenciado. A passagem da modernidade para o contemporâneo será, portanto, marcada pelo trauma ferida aberta na alma por acontecimentos violentos - em que a fala e palavra não encontram mais lugar para serem elaboradas simbolicamente, as feridas não cicatrizam, não podem mais ser curadas através da narrativa. O ensaio de Benjamin constata igualmente o fim da narração tradicional, mas também esboça como que a ideia de uma outra narração, a narrativa contemporânea será essencialmente fragmentária, 'uma narração nas ruínas, uma transmissão entre os cacos de uma tradição em migalhas'.

Em Adieu Monde (1997), de Sandra Kogut, podemos verificar já no trecho inicial do filme o que Gagnebin e Benjamin vêm apontando como traço sintomático do contemporâneo: uma obsessão com o passado, um desejo de volta a uma experiência "autêntica" e "aurática" e o anseio pela volta das tradições orais e da figura do narrador. O filme se inicia com uma sequência em Super 8 , onde vemos uma estrada nos aproximando da pequena vila, campos verdes rodeiam o acostamento, ao fundo uma imponente montanha nevada dos Alpes se prolonga em direção ao céu azul. Imagens que parecem vir de tempos longínquos, uma paisagem idílica e bucólica, como se tirada de um cartão postal ou pintura de Kaspar David Friedrich.

Sandra chega no pequeno vilarejo e vai entrevistando pessoas comuns, habitantes da região. Logo vemos que todos possuem um discurso do "autêntico", um pastor passa com suas ovelhas e duas senhoras exclamam: "Veja, 
ele tem cachorros, este sim é um pastor autêntico". Em outro momento, um homem tenta vender cartões postais para a diretora, afirmando que são "autênticos' - quando claramente podemos perceber que se tratam de fotos impressas. Sandra, no documentário nos mostra um cenário um tanto quanto paradoxal. Consciente da representação de sua própria figura, todos os moradores da aldeia encenam uma narrativa autoficcional, incorporam seus personagens e representam seus papéis. Detentores e guardiões de uma "tradição", eles entram no jogo do turista que os visita em busca da experiência "típica". O local, que a princípio propiciaria um resgate de uma experiência original, gera, por fim, uma produção artificial de uma memória fabricada a fim de suprir uma demanda imaginária, em que um desejo de passado produz uma constante ficcionalização do real.

Em busca de uma suposta "verdadeira" autenticidade, a cineasta pergunta se há algum morador na região que nunca foi filmado: o senhor entrevistado nega. Sandra parte então em busca do imaginário local, pergunta para os moradores com o que eles sonham e pede para contarem lendas, fábulas e mistérios locais. Ela então começa a escutar dos moradores uma mesma história, em versões diferentes: o conto de um pastor Pierre que um dia resolve abandonar suas ovelhas e foge de sua cidade natal. Cada membro da cidade acrescenta uma explicação diferente para o ocorrido, todos garantem que sua versão é a correta, a verdadeira. Sandra então encena a lenda local com dois atores, filmando estas cenas uma Câmera Super 8, imagens que são usadas ao longo da montagem, acompanhadas por uma cantiga típica cantada em dialeto local que narra as desventuras do pastor.

A escolha de Sandra Kogut em usar o Super 8 como um artíficio é bastante evidente. Ao utilizar dois tipos de materialidade das imagens, a diretora opera uma dialética de dois registros do real: a imagem dita como "documental"e atual - feita por Sandra com sua câmera de vídeo Beta-Cam de baixa resolução, na mão - em contraposição às imagens analógicas em Super 8, que conjugam uma representação do onírico, do imaginário coletivo, da tradição oral, de um tempo do passado que não existe mais, de uma França "original" Como no filme de Elena, a imagem analógica no filme de Sandra, em um primeiro momento, nos remete para um passado distante e melancólico, uma imagem que busca uma experiência perdida.

$\mathrm{O}$ analógico surge como uma possibilidade de abertura para uma experiência originária, uma volta da experiência Benjaminiana onde o narrador volta a ter voz. Porém percebemos rapidamente que a imagem Super 8 é absolutamente artificial e fabricada, mais sonhada do que real. Sandra nos coloca diante de um jogo temporal, uma provocação que quebra os paradigmas dos 
discursos da autenticidade. A princípio, a estética do Super 8 remete ao documento histórico, como se estivéssemos presenciando imagens originárias de um tempo passado. Porém rapidamente notamos que as imagens Super 8 são encenadas, que os atores são jovens contemporâneos e que a história está sendo alterada à medida que os habitantes mudam as versões do conto. A estética do Super 8 ocupa o lugar do fantasioso, do desejado, sonhado - enfim o lugar do indiscernível, onde não sabemos se o que estamos vendo é verdadeiro ou falso.Vemos que se trata do imaginário coletivo local, um imaginário que condena a personagem que ousou sair da cidade, ultrapassou as fronteiras e quebrou as tradições, enfim se tornou um ser "globalizado".

Sandra Kogut afirmou em debate sobre o seu filme: "Se filmássemos esse debate hoje com uma câmera Super 8 e projetássemos esse registro dois dias depois, diriamos: Nossa, que lindo! Parece que foi há tantos anos!'. ${ }^{4}$ Sontag (1981: 21) já afirmava que uma fotografia de 1900 nos comove mais hoje em dia pelo fato de ser uma fotografia tirada em 1900 do que pelo seu tema. Para a autora, o tempo acaba colocando a maior parte das fotografias, até as mais amadorísticas, no nível da arte. A autora ainda lembra que Benjamin ao falar de Atget e dos Surrealistas já identificava uma possível beleza naquilo que está em vias de desaparecer: "A aura acena pela última vez na expressão fugaz de um rosto das antigas fotos. " (Benjamin, 1996: 174).

Nesse ponto, podemos fazer um paralelo com outro debate importante na modernidade: o da perda da Aura da obra de arte em razão da reprodutibilidade técnica. Uma das condições (há varias definições possíveis) para uma obra de arte seria possuir uma "aura", nos termos de Walter Benjamin, seria sua capacidade de "retornar" o olhar a seu espectador. É no instante o "olhar correspondido" que provém de um objeto inanimado e surpreende o espectador que a aura se faz notar. Lissovsky (2005) afirma que Aura também pode ser pressentida como o resíduo do passado depositado sobre os objetos, vestígios das mãos que o tocaram, dos olhos que o miraram. A aura é finalmente a marca de uma "origem": "um sopro de pré-história circundando a existência atual". A Aura evocaria a presença de um objeto, que se dá através do contato com o "autêntico" com o "original", que remonta ao passado e à origem do objeto.

Relembremos a etimologia da palavra Fetiche. Vinda da língua portuguesa Feitiço surgida durante a colonização da África oriental na região da Guiné. A palavra seria um neologismo da palavra africana Fetisso, que descreveria as práticas religiosas dos curandeiros que dotavam de poderes mágicos certos ob-

4. Em debate, no dia 02/10/2013, no seminário Cinemáticos organizado por André Parente, no Museu de Arte Moderna do Rio. 
jetos sagrados. Estes objetos deveriam ser tocados pelos sacerdotes ou xamãs para serem dotados de poder. Em um objeto aurático ou fetichizado, se concentra a presença de uma origem que ficou impressa pelo toque e gesto, marcada no objeto através do seu uso no tempo. As coisas que presenciaram ou testemunharam o passado possuem um caráter aurático pois nelas vislumbram-se as memórias e a história social de um povo, em uma forma fragmentada. Um objeto aurático emanaria, portanto, a presença desta origem e não a representaria.

Podemos fazer um paralelo entre este conceito de Aura e Fetiche e aplicálo às materialidades das imagens analógicas cinematográficas. Imagens envelhecidas do passado que possuem marcas físicas impregnadas na superfície como queimaduras, rasgos, sujeiras, toda essa pátina do tempo denota que estas imagens foram tocadas, manipuladas, ou seja, entram em contato físico com algo ou alguém de um passado distante. Assim, por terem entrado em contato com uma "origem"seriam capazes de evocar a volta da aura Benjaminiana. No contemporâneo, novas formas de discurso sobre "Aura" e experiências de presença com as imagens parecem despontar no horizonte das investigações feitas por artistas e cineastas contemporâneos através do suporte analógico. Como na provocação feita por Huyssen:

Com a mudança da fotografia para a sua reciclagem digital, a arte da reprodução mecânica de Benjamin (fotografia) recuperou a aura da originalidade. $\mathrm{O}$ que mostra que o famoso argumento de Benjamin sobre a perda ou o declínio da aura na modernidade era apenas uma parte da história; esqueceu-se que a modernização, para começar, criou ela mesma sua aura. Hoje é a digitalização que dá aura à fotografia "original”. (Huyssen, 2000: 23.).

Em seu tempo, o próprio Benjamin oscilava entre sentimentos de nostalgia por uma experiência tradicional perdida e de entusiasmo pelas novas formas de experiências que viriam a surgir destas transformações industriais, potenciais que ele vislumbrava nas obras dos Surrealistas, de Kafka, Proust e Baudelaire. Para Benjamin, os choques da vivência moderna permitem, através do esquecimento e da rememoração, a retomada de uma experiência em "lampejos de memórias involuntárias".

Em Adieu Monde (1997) e Elena (2012), observamos como o uso das imagens analógicas precárias, "sujas" e envelhecidas parecem ainda fascinar o sujeito contemporâneo. A materialidade e corporeidade das imagens de película parecem estar se reconfigurando como uma nova experiência do olhar, causando uma estranheza que intensifica os sentidos. Sua re-apropriação parecem ser capazes de ensejar anseios, desejos, problemáticas e subjetividades "tipicamente" contempôraneas. 


\section{Referências Bibliográficas}

Aumont, J. (2004). O olho interminável: cinema e pintura. São Paulo: Cosac \& Naify.

Barthes, R. (1984). A câmara clara. Rio de Janeiro: Nova Fronteira.

Bazin, A. (2014). O que é o Cinema. Editora Cosac \& Naify, $1^{\text {a }}$ Edição.

Benjamin, W. (2000). A modernidade e os modernos. Rio de Janeiro: Tempo Brasileiro, $2^{\mathrm{a}}$ Ed.

Benjamin, W. (1996). Obras escolhidas. magia e técnica, arte e política, vol. 1. Editora Brasiliense.

Charney, L. \& Schwartz, V. (2004). O cinema e a invenção da vida moderna. São Paulo: Cosac Naif, $2^{\mathrm{a}}$ Ed.

Deleuze, G. (2005). A imagem-tempo. São Paulo: Brasiliense.

Dubois, P. (2014). Cinema, vídeo, Godard. São Paulo: Cosac Naif.

Dubois, P. (2009). O ato fotográfico e outros ensaios. Campinhas: E. Papirus.

Gagnebin, J. M. (2006). Lembrar, escrever, esquecer. São Paulo: Editora 34.

Huyssen, A. (2014). Culturas do passado-presente: modernismos, artes visuais, políticas da memória. Rio de Janeiro: Contraponto.

Huyssen, A. (2000). Seduzidos pela memória: arquitetura, monumentos e mídia. Rio de Janeiro: Coleção Agenda do Milênio. Editora UCAM, Aeroplano.

Krauss, R. (2010). O fotográfico. Barcelona, Espanha: Editions Macula, $1^{\mathrm{a}}$ Ed.

Lissovsky, M. (2005). A memória e as condições poéticas do acontecimento. O que é memória social? (pp. 133-214). Rio de Janeiro: Contracapa.

Marks, L. (2000). The skin of the film. Intercultural cinema, embodiment and the senses. Durham and London: Duke University Press.

Machado, A. (2011). Pré-cinemas \& pós-cinemas. Campinas, Sp: Papirus, $6^{\mathrm{a}}$ ed.

Xavier, I. (org.) (1983). A experiência do cinema: antologia. Rio de Janeiro: Edições Graal, Embrafilme. 


\section{Anexos}

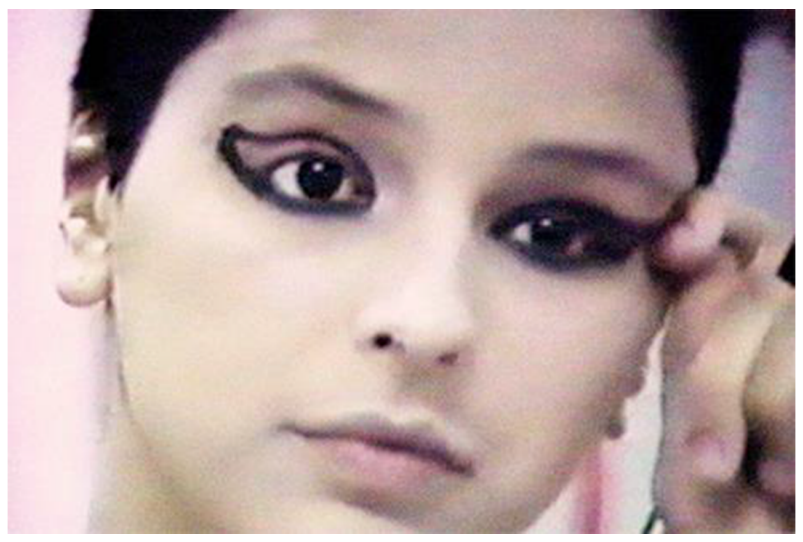

Still do Filme Elena (2012), de Petra Costa - VHS.

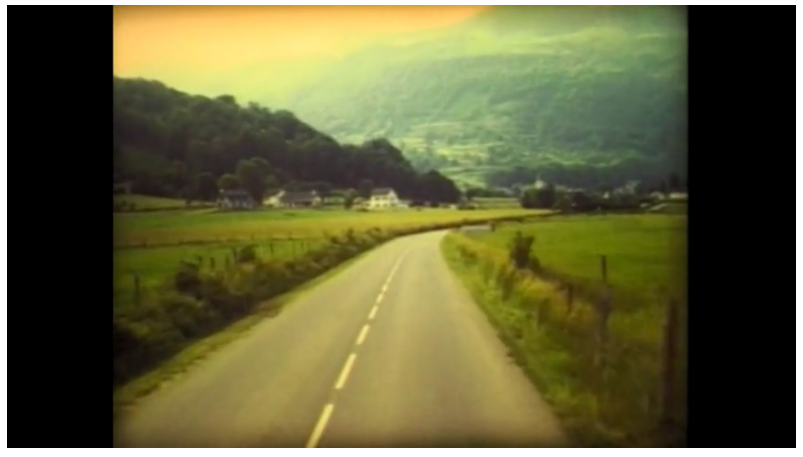

Adieu Monde (1997), de Sandra Kogut - Super 8. 